\title{
Editorial
}

\section{Dos and don'ts in scholarly publishing}

Maritime Economics \& Logistics (2016) 18, 101-102. doi:10.1057/mel.2016.19

Publishing in a good journal is not as difficult as it may appear at first sight; but there are rules on how this game should be played. Universities even exist today, giving courses on how to interact with your editor. The few points below are intended as a 'check list', throughout the publishing process, until you see your name in print.

When choosing a journal, try first to understand its 'scope and objectives' so as to satisfy yourself that your paper 'fits' there. Otherwise you may be losing your time and eventually receive a frustrating negative decision. The prestige of the journal itself is less important. What is important is to select a journal where your paper will have the highest impact (we have seen papers in the most prestigious international journals, albeit with 3 citations in 5 years).

When you draft your paper, do so with your reader in mind and, starting from the abstract, try to make your paper as 'appetizing' as possible, constantly ensuring that your reader will continue reading it to the very end. Your abstract is crucial in this respect. This is the place where you should tell what is innovative in your paper, or why your paper had to be written, over and above everything else that has appeared before you.

Decide who your reader is and write accordingly. Does your paper intend to address people of theoretical background, or business and policy makers? In other words, is your main contribution a methodological one, or does it have policy implications of direct applicability? This decision should determine the choice of journal, your writing style, and the contents of your paper (for example, the desirability of full exposition of technical detail, in a paper whose value is in its policy recommendations).

Never argue with a referee; it is unlikely you will win this discourse. Once your paper has been assessed as one worth looking at further, referees are there to help you publish. To the best of your ability, try to comply to their requests rather than argue how right you are. When a referee asks a question, he does not only expect an answer but rather to see that answer reflected in your text. Avoid journals with poor reputation on the 'rigor' of their reviewing process. Would you really submit again to a journal which has accepted your previous paper just by informing you that 'this is a good paper and we would like to publish it'? Remember: your objective is to publish a good paper and not just 'words in print'.

(C) 2016 Macmillan Publishers Ltd. 1479-2931 Maritime Economics \& Logistics Vol. 18, 2, 101-102 www.palgrave-journals.com/mel/ 
It is quite common among young researchers, particularly PhD students, to want to publish as sole authors. Nothing could be more wrong than this. Today we are overwhelmed by information and our reading time is limited. No matter how good your paper is, the chances of it being read (and cited) are much thinner, than were you to co-author it with a well-known scholar; for example, your supervisor. And don't forget: the objective is 'citations' rather than seeing your name in print.

Writing is an art. A lot of otherwise technically excellent papers are rejected because of poor style and English. Your reader doesn't have the time to decipher what you 'would like' to say. Try to be succinct and to the point. Use short sentences. Avoid wordiness and repetition. Saying something once should suffice. Before submitting, always ask a couple of your colleagues (hopefully native English speakers) to have a look and comment.

Long literature reviews are not usually appreciated by many readers who often tend to skip them. Stick to works that are relevant to yours, that is, works that you have actually used in the development of your paper. When reviewing a work, rather than describing what that author has done, try instead to discuss his conclusions and the way they impact yours.

Depending on how the journal has prioritized your paper, reviewing time can be quite lengthy and good referees are a 'scarce commodity'. An occasional inquiry would be appreciated but don't overdo it.

Finally, there is the big question of 'publishing ethics'; for example, submitting your paper simultaneously to more than one journals, or publishing it electronically at various depositories while your paper is under consideration. Many journals blacklist such authors. On this I would advise you to take a good look at COPE: Committee on Publication Ethics - www.publicationethics.org which I am sure you will find very enlightening.

Good luck with your research and I am looking forward to considering it in MEL.

H E Haralambides

Editor-in-Chief

Maritime Economics and Logistics. 